\title{
Community genetics in Brazil
}

\section{Introduction}

Community genetics services include a number of activities with different complexities for the diagnosis, care and prevention of genetic diseases at community level. The goal of community genetics in lowand middle-income countries is to prevent congenital disorders and genetic diseases at population level and, at the same time, to provide genetics services (diagnosis and counselling) in the community for individuals and families. ${ }^{1}$

\section{Congenital disorders epidemiology in Brazil}

In Brazil, epidemiological information on congenital disorders is obtained through liveborn declaration, official document issued by maternities. Such declaration allows congenital anomalies present at birth to be registered systematically. It has yes or no question for the presence of congenital malformation plus an open field provided for the description and classification of the all observed defects according to ICD-10 (Table 1). ${ }^{2}$

Table I Congenital Anomalies. Declared cases

\begin{tabular}{ll}
\hline Brazil 2015 type of congenital anomaly & N' cases \\
\hline Spina bifida & 611 \\
Other congenital malformations of the nervous system & 3199 \\
Congenital malformations of the circulatory system & 2127 \\
Cleft hp and cleft palate & 1524 \\
Absence, atresia and stenosis of the small intestine & 37 \\
Other congenital malformations of the digestible tract & 997 \\
Undescended testicle & 417 \\
Other malformations of the genitourinary tract & 1843 \\
Congenital hip deformities & 134 \\
Congenital deformities of the feet & 2622 \\
$\begin{array}{l}\text { Other congenital deformities of the musculoskeletal } \\
\text { system }\end{array}$ & 6139 \\
Other congenital malformations & 3301 \\
Chromosomal abnormalities & 1049 \\
Congenital syphilis & no records \\
sernangioma e lymphoma & 98 \\
Dentofaciat anormalies & no records \\
Other affections compromising tegument specific to \\
the fetus or newborn \\
Without congenital anOmaly/uninformed \\
no records \\
selected \\
2.993 .224
\end{tabular}

By analyzing data available through the DATASUS website related to births in Brazil in 2015, last year available in the database, only 0 , $81 \%$ of newborns were registered as having a congenital anomaly, suggesting that such anomalies are being underreported. ${ }^{3}$
Volume 9 Issue $6-2018$

\author{
Flávio Xavier da Silva \\ Doctoral student in Obstetrics and Gynecology, Universidade \\ de Campinas (UNICAMP), Brazil
}

Correspondence: Flávio Xavier da Silva, Doctoral student in Obstetrics and Gynecology, Universidade de Campinas (UNICAMP), Campinas, SP, Master's degree in Maternal-Child Health from IMIP, Recife, PE, Brazil,Tel (8I)99666-9258, Email flavio-xavier@live.com

Received: April 06, 2018| Published: December 27, 2018

\section{Medical genetic services available in Brazil}

Medical genetic services are available in some of main cities in Brazil, although in the South-east region, mainly in São Paulo state, are the majority of both private and public services. These services include those related to laboratories, integrated to clinical centers and to medical schools. ${ }^{4}$

Some genetic services were identified in Brazil by ECLAMC (Estudo Colaborativo Latino Americano) and INAGEMP (Instituto Nacional de Genética Médica Populacional). ECLAMC exists since 1967 and is recognized as a collaborative center of World Health Organization (WHO) for prevention of congenital diseases and covers all Latin America. ${ }^{2,4}$

\section{Existing actions in Brazil related to congenital defects}

There are programs to prevent and investigate congenital disorders in the preconception, prenatal care and after birth in health posts, polyclinics and tertiary hospitals. $^{2}$

Preconception, the couple can seek the family planning services to take folic acid. Informations about contraceptive methods have also been given. In the case of couple with an afected child, counseling and investigation can be offered and, if necessary, referral to specialized services. $^{5}$

In prenatal care, hemoglobin electrophoresis is requested in the first prenatal consultation. Congenital infections are routinely searched, such as: hepatite B, HIV, syphilis and toxoplasmosis. Diabetes and anemia are also searched. Ultrasound can be requested, if it is available. ${ }^{5}$

Newborns are undergoing to "pezinho" exam to diagnose of six congenital diseases up to fifth day of life: phenylketonuria, congenital hypothyroidism, sickle cell disease, cystic fibrosis, biotinidase deficiency and congenital adrenal hyperplasia. Brazil health system guarantees suitable treatment and the follow up for all life. ${ }^{6}$

\section{Factors can contribute to rates of congenital disorders become higher in Brazil}

a. Microcephaly epidemic associated to Zika virus infection in 2015. It has been estimated that in 2016 occurred 508 confirmed cases of microcephaly. In contrast, during period between 2010 and 2014, the annual mean of microcephaly cases reported was $163 .^{7}$ 
b. Brazil is a tropical country that contributes to increase congenital toxoplasmosis. In some regions, the incidence of this disease can reach 14 cases per 10,000 live births. Most of them are symptomatic and the main findings are retinochoroiditis, intracranial calcifications and altered cerebrospinal fluid. ${ }^{8}$

c. The number of cases of syphilis has absurdly been increasing in recent years. ${ }^{9}$

d. Alcoholism in pregnant women is associated with a spectrum of abnormalities, referred to as fetal alcohol spectrum disorders (FASD). FASD include growth deficiencies on height and weight, microcephaly, smooth philtrum, thin vermillion border, and short palpebral fissures. It was related that almost $40 \%$ of adolescent mothers use alcohol in pregnancy in southern Brazil. ${ }^{10,11}$

e. New cases of phocomelia (limb reduction defects of long bones, in which hands and feet varied between normal and rudimentary) were reported in different parts of the country despite the restrictions imposed on the use of thalidomide. The occurrence is attributed to the high incidence of leprosy in Brazil and poor control for this drug. ${ }^{12}$

\section{Conclusion}

i. Immunization and sanitary programs are fundamental to the control of the tropical diseases

ii. There are needs adequate fill of liveborn declarations so that official data becomes more consistent with our reality

iii. Rapid test at the first antenatal visit has to be intensified for early diagnosis and treatment of syphilis. Providing penicilinas for syphilis treatment in health services as well

iv. Programs to combat alcohol use in pregnancy

v. Obtaining a safe form of thalidomide is a common goal of both the scientific community and thalidomide users.

\section{Acknowledgments}

None.

\section{Conflicts of interest}

The author declares that they do not have any conflicts of interest.

\section{References}

1. WHO. Community genetics services: report of a WHO consultation on community genetics in low- and middle-income countries. 2011.

2. Horovitz D, Dain V, Marques-de-Faria A. Genetic services and testing in Brazil. J Community Genet. 2013;4(3):355-375.

3. Brazil. Ministry of Health. DATASUS - SUS Department of Informatics. Vital Health Information/Statistics.

4. Horovitz D, Llerena Jr. J, Mattos R. Birth defects and health strategies in Brazil: an overview. Cad. Saúde Pública. 2005;21(4):1055-1064.

5. Brazil. Ministry of Health: Women's Health/Ministry of Health, Instituto Sírio-Libanês de Ensino e Pesquisa - Brasília: Ministry of Health, 2016. $230 \mathrm{p}$

6. Brazil. Ministry of Health. Secretariat of Health Care. Department of Specialized and Thematic Attention. Biological neonatal screening: technical manual. Brasília: Ministry of Health, 2016. 80 p.

7. Heukelbach J, Alencar C, Kelvin A, et al. Zika virus outbreak in Brazil. $J$ Infect Dev Ctries. 2016;10(2):116-120.

8. Bischoff A, Friedrich L, Cattan J, et al. Incidence of symptomatic congenital toxoplasmosis during ten years in Brazilian hospital. Pediatr Infect Dis J. 2016;35(12):1313-1316.

9. Brazil. Ministry of Health. Secretariat of Health Surveillance. Epidemiological Bulletin. Sifilis. 2017;48(36):1-41.

10. Feldman H, Jones K, Lindsay S, et al. Prenatal alcohol exposure patterns and alcohol-related birth defects and growth deficiencies: a prospective study. Alcohol Clin Exp Res. 2012;36(4):670-676.

11. Momino W, Félix T, Abeche A, et al. Maternal drinking behavior and Fetal Alcohol Spectrum Disorders in adolescents with criminal behavior in southern Brazil. Genetics and Molecular Biology. 2012;35(4):960965.

12. Sales Luiz Vianna F, Kowalski TW, Fraga LR, et al. The impact of thalidomide use in birth defects in Brazil. European Journal of Medical Genetics. 2017;60:12-15. 